\title{
Study on the Satisfaction for Resident Community Services in Weicheng District of Weifang City in the Background of First Diagnosis in the Community*
}

\author{
Shanshan Li \\ School of Management \\ Jining Medical University \\ Rizhao, China \\ School of Economics, Sichuan University \\ Chengdu, China
}

\author{
Hong Zheng** \\ Sichuan Maternal and Child Care Service Centre \\ Chengdu, China \\ **Corresponding Author
}

\author{
Lirong Xu \\ School of Management \\ Jining Medical University \\ Rizhao, China
}

\begin{abstract}
Objective: To understand the operation situation of community first diagnosis in Weicheng District of Weifang City, to study the influencing factors of residents' degree of satisfaction with community health service organizations, and to analyze the existing problems and propose countermeasures. Methods: We have applied the stratified sampling approach, and randomly selected 200 permanent residents over 20 years old in 12 communities in 6 blocks of Weicheng District of Weifang City for questionnaire survey. The software of SPSS 21.0 was used for statistical analysis. Results: The survey showed that after illness, $61(31.8 \%)$ of the residents first selected community health service organizations, $125(65.1 \%)$ preferred non-community health service organizations, and $6(3.1 \%)$ didn't plan to seek for treatment. Single factor analysis shows that the health status of residents, the distance to the nearest medical service institutions, the proportion of half-year medical expenses to half-year income, preferred medical service institutions, degree of trust in community health service institutions, rationality of preferring community health service institutions for medical treatment, and whether the level and conditions of medical treatment in community health service institutions were improved are statistically significant $(P<0.05)$ for the differences in the degree of satisfaction with community health service institutions. Conclusions Residents' degree of satisfaction with community health service institutions is high, but residents' willingness of preferring community health service organizations to seek medical treatment after illness is still to be strengthened, and community health service capacity needs to be improved.
\end{abstract}

Keywords-community first diagnosis; community service; influencing factors; degree of satisfaction

*This article is the phased research result of the Jining Medical University Teacher Scientific Research Support Project (JY2017RW003) and the Jining Medical University Student Scientific Research Project (JYXS2017RW011)

\section{INTRODUCTION}

The community first diagnosis system refers to the system that when residents are sick and need to see a doctor, in addition to the emergency patients who can be referred to hospitals by community general practitioners for specialist medical services, non-emergency patients must first go to community health service organizations for medical treatment by general practitioners[1]. Community health services are not only to provide basic medical services, the underlying purpose is to prevent and control diseases and promote health[2]. In 2015, in the "Guiding Opinions of the General Office of the State Council on Promoting the Construction of Graded Diagnosis and Treatment System (issued by the General Office of the State Council [2015] No. 70)", it was proposed to "gradually form the graded diagnosis and treatment system of first diagnosis in grass-roots units, two-way referral, division of treatments for emergency and non-emergency diseases, and linkages between the higher-level and lower-level institutions", encouraging and gradually regulating patients who have common diseases or frequently-occurring diseases to first go to the primary health care institutions for treatment, and by 2020 , achieving the goal of comprehensively improving the service ability of graded diagnosis and treatment. It can be seen that the community first diagnosis system is the core element of the graded diagnosis and treatment system and the key to establishing hierarchical and reasonable community health services. [3] Residents' degree of satisfaction with community health services is one of the important criteria for measuring the smooth running of the community first diagnosis system. Therefore, we have selected the Weifang City, a pilot area of the grading diagnosis and treatment system and the family doctor contracting system, as the research object, and explored residents' degree of satisfaction with community services and 
existing problems in the implementation of the community first diagnosis, and proposed solutions.

\section{OBJECTS AND METHODS}

Use the stratified random sampling method, regard the 6 blocks in Weicheng District of Weifang City as 6 different groups. Randomly select 2 communities in each group, and select a total of 12 communities, and then choose 200 permanent residents over 20 years old for the questionnaire survey. 200 questionnaires were distributed in JanuaryFebruary 2018, and 192 valid questionnaires were collected. The effective recovery rate was $96.0 \%$. The software of Excel 2010 was used to establish database for data entry. And the software of SPSS 21.0 was used for statistical analysis. Single factor comparison was performed in the form of $\chi^{2}$ test. Multivariate analysis was performed by using Logistic stepwise regression method. $\mathrm{P}<0.05$ was considered statistically significant.

\section{RESULTS}

\section{A. Basic Conditions}

Among the 192 persons, gender: 88 males (45.83\%), 104 females (54.17\%); age: 63 people aged $20-30$ years $(32.81 \%)$, 42 people aged $31-40(21.88 \%)), 49$ people aged $41-50$ (25.52\%), 23 people aged 51-60 (accounting for 11.98\%), 15 people aged 60 and over $(7.81 \%)$; occupation: 100 employees (52.08\%), 18 retirees $(9.38 \%), 15$ students $(7.81 \%), 30$ persons waiting for employment (15.63\%), 29 unemployed persons $(15.10 \%)$; Education: 30 persons graduated from primary or lower schools $(15.63 \%), 89$ people graduated from secondary schools $(46.35 \%), 65$ people graduated from undergraduate schools or academies (33.85\%), 8 persons were postgraduates or above $(4.17 \%)$; monthly income: 62 people have the income of below 2000 yuan (32.29\%), 45 people of 2000 - 3000 yuan (accounting for 23.44\%), 48 people of 3000-4000 yuan (accounting for 25.00\%), 19 people of 4000-5000 yuan (accounting for 9.90\%), 18 people of 5,000 yuan or more (accounting for $9.38 \%$ ); type of medical insurance : 155 people have the urban and rural residents' medical insurance (accounting for 80.73\%), 25 people have the urban workers' medical insurance (13.02\%), 8 people have the commercial insurance $(4.17 \%), 4$ people have bought the medical insurance by themselves (2.08\%); health status: very good 119 persons (accounting for 61.98\%), relatively good 48 persons (25.00\%), general 23 persons (11.98\%), poor 2 persons(1.04\%); knowledge of the community health service organizations: well know 48 persons $(25.00 \%)$, generally know 112 people (accounting for $58.33 \%$ ), don't know 32 people (accounting for $16.67 \%$ ).

\section{B. The First Diagnosis Behaviors}

After being ill, 125 people $(65.1 \%)$ first selected the community health service organizations for medical treatment, $61(31.8 \%)$ preferred non-community health service organizations, and $6(3.1 \%)$ said they would not seek for treatment. Among the surveyed different characteristics of residents, only the occupation was statistically significant for residents' first diagnosis behaviors $(\mathrm{P}<0.05)$; while gender, age, education level, monthly income, health status, type of medical insurance, knowledge of community health service institutions and the distance to the nearest medical service institution were not statistically significant for residents' first diagnosis behaviors $(\mathrm{P}>0.05)$ "Table I"

TABLE I. COMPARISON OF FIRST DIAGNOSIS BEHAVIORS OF RESIDENTS WITH DIFFERENT CHARACTERISTICS [N(\%)]

\begin{tabular}{|c|c|c|c|c|c|}
\hline \multirow[b]{2}{*}{$\begin{array}{l}\text { Influencing } \\
\text { Factor }\end{array}$} & \multirow[b]{2}{*}{$\begin{array}{l}\text { Number } \\
\text { of Cases }\end{array}$} & \multicolumn{2}{|c|}{ First Diagnosis Behavior } & \multirow[b]{2}{*}{$\begin{array}{l}\text { Chi- } \\
\text { Square } \\
\text { Value }\end{array}$} & \multirow[b]{2}{*}{$\begin{array}{c}\mathbf{P} \\
\text { Value }\end{array}$} \\
\hline & & $\begin{array}{c}\text { Community } \\
\text { health } \\
\text { service } \\
\text { institutions } \\
\end{array}$ & $\begin{array}{c}\text { Non- } \\
\text { community } \\
\text { health service } \\
\text { institutions }\end{array}$ & & \\
\hline Occupation & & & & 18.651 & 0.017 \\
\hline Employees & 97 & $67(69.1)$ & $30(30.9)$ & & \\
\hline Retirees & 18 & $11(61.1)$ & $7(38.9)$ & & \\
\hline $\begin{array}{l}\text { Unemployed } \\
\text { persons }\end{array}$ & 15 & 13(86.7) & $2(13.3)$ & & \\
\hline $\begin{array}{l}\text { Persons } \\
\text { waiting for } \\
\text { employment }\end{array}$ & 30 & $15(50.0)$ & $15(50.0)$ & & \\
\hline Students & 26 & $18(69.2)$ & $8(30.8)$ & & \\
\hline
\end{tabular}

The reasons why the residents preferred community health service institutions for treatment after being sick are the transportation is convenient $(72.8 \%)$, medical expenses are low $(48.8 \%)$, their sickness was not serious $(57.6 \%)$, the service attitude is good $(12.0 \%)$, it can save time $(44.0 \%)$, and the doctors are good (6.4\%), etc. "TableII"

TABLE II. REASONS FOR RESIDENTS' PREFERRING COMMUNITY HEALTH SERVICE INSTITUTIONS FOR TREATMENT(N=125)

\begin{tabular}{lll}
\hline \multicolumn{1}{c}{ Reasons } & \multicolumn{1}{c}{$\begin{array}{c}\text { Number of Persons } \\
\text { Choosing This Reason }\end{array}$} & $\begin{array}{c}\text { Choosing Rate } \\
(\boldsymbol{\%})\end{array}$ \\
\hline $\begin{array}{l}\text { Convenient } \\
\text { transportation }\end{array}$ & 91 & 72.8 \\
$\begin{array}{l}\text { Low medical } \\
\text { expenses }\end{array}$ & 61 & 48.8 \\
$\begin{array}{l}\text { Not serious } \\
\text { Good service }\end{array}$ & 72 & 57.6 \\
$\begin{array}{l}\text { attitude } \\
\text { Save time }\end{array}$ & 55 & 12.0 \\
$\begin{array}{l}\text { Doctors are good at } \\
\text { treating deceases }\end{array}$ & 8 & 44.0 \\
\hline
\end{tabular}

Reasons for the residents to prefer non-community health service organizations for treatment are these organizations have high medical level and advanced technologies $(86.9 \%)$, the medical facilities in community health service organizations are poor $(32.8 \%)$, the doctors in community health service organizations lack experience $(16.4 \%)$, there are inadequate drugs in community health service organizations $(13.1 \%)$, and large and medium-sized general hospitals are designated social security hospitals (32.8\%), etc. "Table III" 
TABLE III. REASONS FOR RESIDENTS TO PREFER NON-COMMUNITY HEALTH SERVICE INSTITUTIONS FOR TREATMENT(N=61)

\begin{tabular}{lll}
\hline \multicolumn{1}{c}{ Reasons } & $\begin{array}{c}\text { Number of } \\
\text { People } \\
\text { Choosing This } \\
\text { Reason }\end{array}$ & $\begin{array}{c}\text { Choosing Rate } \\
(\%)\end{array}$ \\
\hline High medical treatment level & 53 & 86.9 \\
$\begin{array}{l}\text { Poor medical facilities in } \\
\text { community health service } \\
\text { organizations } 20\end{array}$ & 32.8 \\
$\begin{array}{l}\text { Lack of experience of the doctors } \\
\text { in community health service } \\
\text { organizations }\end{array}$ & 10 \\
$\begin{array}{l}\text { Inadequate drugs in community } \\
\text { health service organizations }\end{array}$ & \\
$\begin{array}{l}\text { Large and medium-sized general } \\
\text { hospitals are designated social } \\
\text { security hospitals }\end{array}$ & 20 & 32.4 \\
\hline
\end{tabular}

\section{Residents' Satisfaction Conditions with Community Health} Service Institutions and the Influencing Factors

Among the 192 people, $171(89.1 \%)$ said that they were satisfied with the community health service organizations, and
$21(10.9 \%)$ were dissatisfied with the community health service organizations. Residents are dissatisfied with the community health service institutions due to their poor environment $(41.7 \%)$, bad service attitude (16.7\%), short diagnosis and treatment time (16.7\%), too many misdiagnosis cases $(16.7 \%)$, and too many unreasonable charges $(8.3 \%)$, etc. "Table IV"

TABLE IV. REASONS WHY RESIDENTS ARE DISSATISFIED WITH COMmunity HEALTH SERVICE INSTITUTIONS (N=21)

\begin{tabular}{lll}
\hline \multicolumn{1}{c}{ Reasons } & $\begin{array}{c}\text { Number of Persons Choosing This } \\
\text { Reason }\end{array}$ & $\begin{array}{c}\text { Choosing Rate } \\
(\boldsymbol{\%})\end{array}$ \\
\hline $\begin{array}{l}\text { Poor environment } 15 \\
\text { Bad service attitude }\end{array}$ & 41.7 \\
Short diagnosis and6 $\quad 6$ & 16.7 \\
treatment time many6 & 16.7 \\
Too many3 & 16.7 \\
misdiagnosis cases & \\
Too \\
unreasonable charges
\end{tabular}

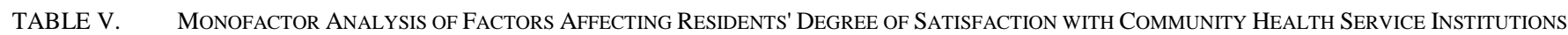
$[\mathrm{N}(\%)]$

\begin{tabular}{|c|c|c|c|c|c|}
\hline \multirow{2}{*}{ Influencing Factor } & \multirow{2}{*}{$\begin{array}{l}\text { Number } \\
\text { of Cases }\end{array}$} & \multicolumn{2}{|c|}{$\begin{array}{l}\text { Satisfied or Unsatisfied with Community } \\
\text { Health Service Institutions }\end{array}$} & \multirow{2}{*}{$\begin{array}{l}\text { Chi-Square } \\
\text { Value }\end{array}$} & \multirow{2}{*}{$\begin{array}{r}\mathrm{P} \\
\text { value }\end{array}$} \\
\hline & & Satisfied & Unsatisfied & & \\
\hline state of health & & & & 16.739 & 0.001 \\
\hline very good & 119 & $106(89.1)$ & $13(10.9)$ & & \\
\hline relatively good & 48 & $44(91.7)$ & $4(8.3)$ & & \\
\hline general & 23 & 21(91.3) & $2(8.7)$ & & \\
\hline relatively bad & 2 & 0 & $2(100.0)$ & & \\
\hline very bad & 0 & 0 & 0 & & \\
\hline Distance to the nearest medical service institution $(\mathrm{km})$ & & & & 10.136 & 0.006 \\
\hline$<5$ & 159 & $142(89.3)$ & $17(10.7)$ & & \\
\hline $5 \sim 10$ & 30 & $28(93.3)$ & $2(6.7)$ & & \\
\hline $10 \sim 50$ & 3 & $1(33.3)$ & $2(66.7)$ & & \\
\hline$>50$ & 0 & 0 & 0 & & \\
\hline The proportion of half-year medical expenses to half-year income & & & & 25.251 & 0.001 \\
\hline $20 \%$ or less & 158 & $144(91.1)$ & $14(8.9)$ & & \\
\hline $21 \% \sim 50 \%$ & 31 & $27(87.1)$ & $4(12.9)$ & & \\
\hline $51 \% \sim 80 \%$ & 2 & 0 & $2(100.0)$ & & \\
\hline $81 \%$ or more & 1 & 0 & $1(100.0)$ & & \\
\hline Preferred medical service institution & & & & 10.118 & 0.006 \\
\hline Community health service institutions & 61 & 48(78.7) & $13(21.3)$ & & \\
\hline Non-community health service institutions & 125 & $117(93.6)$ & $8(6.4)$ & & \\
\hline Will not seek for treatment & 6 & $6(100)$ & 0 & & \\
\hline Degree of reassurance of community health service institutions & & & & 43.514 & 0.001 \\
\hline Rest assured & 93 & $78(83.9)$ & $15(16.1)$ & & \\
\hline Relatively rest assured & 91 & $88(96.7)$ & $3(3.3)$ & & \\
\hline Not rest assured & 8 & $5(62.5)$ & $3(37.5)$ & & \\
\hline $\begin{array}{l}\text { Rationality of preferring community health service institutions } \\
\text { treatment }\end{array}$ & for medical & & & 24.662 & 0.001 \\
\hline Reasonable & 171 & $159(93.0)$ & $12(7.0)$ & & \\
\hline Unreasonable & 21 & $12(57.1)$ & $9(42.9)$ & & \\
\hline $\begin{array}{l}\text { Whether the level and conditions of medical treatment in com } \\
\text { improved }\end{array}$ & nunity healtl & service institutic & & 22.814 & 0.001 \\
\hline Yes & 156 & 147(94.2) & $9(5.8)$ & & \\
\hline No & 36 & $24(66.7)$ & $12(33.3)$ & & \\
\hline
\end{tabular}


Monofactor analysis showed that the health status of residents, the distance to the nearest medical service organization, the ratio of half-year medical expenses to halfyear income, the preferred medical service organization, the level of reassurance to community health service organizations, the rationality of preferring community health service institutions for medical treatment, and the level and conditions of medical treatment in community health service institutions were all statistically significant for the differences in the degree of satisfaction with community health service institutions ( $\mathrm{P}<0.05$, "Table V"); Gender, age, occupation, education level, monthly income, type of medical insurance, knowledge of community health service institutions and number of visits had no statistically significance for the differences in the degree of satisfaction with community health service institutions $(\mathrm{P}>0.05)$. Set "Whether residents are satisfied with their community health service institutions" as the dependent variable ( 0 means "unsatisfied", 1 means "satisfied"), and the variables statistically significant in the monofactor analysis as independent variables, and establish a binary logistic regression model. The specific variable design is shown in "Table VI". It can be seen from Table VII that the proportion of half-year medical treatment cost to half-year income, the rationality of preferring community health service institutions for medical treatment, and the level and condition of medical treatment in community health service institutions are the factors that affect residents' degree of satisfaction with their community health service institutions $(\mathrm{P}<0.05)$. The value of Cox \& Snell R2 is $20.8 \%$, the value of Nagelkerke R2 is $41.7 \%$, and the $\mathrm{P}$ value of the chi-square value of Hosmer and Lemeshow test is $0.158>0.05$, indicating that the model fits well.

TABLE VI. VARIABLE DESIGN

\begin{tabular}{|c|c|c|c|}
\hline $\begin{array}{l}\text { Category of } \\
\text { Variable }\end{array}$ & Symbol & Variable & Value \\
\hline \multirow[t]{3}{*}{$\begin{array}{l}\text { Dependent } \\
\text { variable }\end{array}$} & $\mathrm{Y}$ & $\begin{array}{l}\text { Satisfied or unsatisfied with the services of the community health } \\
\text { service organization }\end{array}$ & $\begin{array}{l}Y=0, \text { unsatisfied } \\
Y=1, \text { satisfied }\end{array}$ \\
\hline & a7 & Health status & $\begin{array}{l}\text { a7 }=1, \text { very good } \\
\text { a7 }=2 \text {, relatively good } \\
\text { a7 }=3 \text {, general } \\
\text { a7 }=4 \text {, relatively bad } \\
\text { a7 }=5 \text {, very bad }\end{array}$ \\
\hline & b1 & Distance to the nearest medical service institution & $\begin{array}{l}\text { b1 }=1, \text { within } 5 \mathrm{~km} \\
\text { b2 }=2,5-10 \mathrm{~km} \\
\text { b2 }=3,10-50 \mathrm{~km} \\
\text { b2 }=4, \text { More than } 50 \mathrm{~km}\end{array}$ \\
\hline \multirow[t]{5}{*}{$\begin{array}{l}\text { Independent } \\
\text { variables }\end{array}$} & b3 & The proportion of half-year medical expenses to half-year income & $\begin{array}{l}\text { b3 }=1, \text { less than } 20 \% \\
\text { b3 }=2,21-50 \% \\
\text { b3 }=3,51-80 \% \\
\text { b3 }=4, \text { more than } 81 \%\end{array}$ \\
\hline & b4 & Preferred medical service institution & $\begin{array}{l}\text { b4 }=1 \text {, community health service institutions } \\
\text { b4 }=2 \text {, non-community health service institutions }\end{array}$ \\
\hline & b9 & Degree of reassurance of community health service institutions & $\begin{array}{l}\mathrm{b} 9=1, \text { not rest assured } \\
\mathrm{b} 9=2 \text {, relatively rest assured } \\
\mathrm{b} 9=3 \text {, rest assured }\end{array}$ \\
\hline & b10 & $\begin{array}{l}\text { Rationality of preferring community health service institutions for } \\
\text { medical treatment }\end{array}$ & $\begin{array}{l}\text { b10 }=1, \text { unreasonable } \\
\text { b10 }=2, \text { reasonable }\end{array}$ \\
\hline & b11 & $\begin{array}{l}\text { Whether the level and conditions of medical treatment in } \\
\text { community health service institutions are improved }\end{array}$ & $\begin{array}{l}\text { b11 }=1, \text { yes } \\
\text { b11=2,no }\end{array}$ \\
\hline
\end{tabular}

TABLE VII. Multivariate LOGISTIC REGRESSION ANALYSIS OF FACTORS INFLUENCING RESIDENTS' DEGREE OF SATISFACTION WITH COMMUNITY HEALTH SERVICE INSTITUTIONS

\begin{tabular}{lccccccc}
\hline variable & \multirow{2}{*}{$\mathbf{B}$} & \multirow{2}{*}{ S.E, } & Wals & \multirow{2}{*}{ Sig. } & \multirow{2}{*}{ Exp $(\mathbf{B})$} & \multicolumn{2}{c}{ 95\% C.I. of EXP(B) } \\
\cline { 7 - 8 } & & & & & Lower limit & Upper limit \\
\hline a7 & 0.757 & 0.499 & 2.305 & 0.129 & 2.132 & 0.802 & 5.666 \\
b1 & -0.353 & 0.598 & 0.349 & 0.555 & 0.702 & 0.217 & 2.268 \\
b3 & -1.900 & 0.785 & 5.853 & 0.016 & 0.150 & 0.032 & 0.697 \\
b4 & -0.398 & 0.569 & 0.490 & 0.484 & 0.672 & 0.220 & 2.049 \\
b9 & 0.810 & 0.462 & 3.080 & 0.079 & 2.249 & 0.910 & 5.560 \\
b10 & 2.081 & 0.690 & 9.091 & 0.003 & 8.016 & 2.072 & 31.017 \\
b11 & 2.105 & 0.591 & 12.709 & 0.000 & 8.209 & 2.580 & 26.119 \\
Constant & -4.643 & 2.511 & 3.418 & 0.064 & 0.010 & & \\
\hline
\end{tabular}




\section{DISCUSSIONS}

\section{A. The Proportion of Medical Expenses to Income Is Too High}

The monofactor analysis shows that the proportion of residents' half-year medical expenses to half-year income is statistically significant for the differences in residents' degree of satisfaction with community health service institutions. The multivariate logistic regression analysis shows that the proportion of residents' half-year medical expenses to half-year income is the influencing factor of residents' degree of satisfaction with the health service institutions in their communities, and has a significant negative impact. The higher the proportion of medical expenses to income is, the more unsatisfied residents tend to be. Government's insufficient regulation and control of medical insurance policies and inadequate compensation for community first diagnosis are likely to lead to the high cost of medical treatment for residents, making medical expenses account for a large share of residents' income, and increasing residents' medical treatment economic burden.

The implementation of the medical insurance system plays an important role in policy regulation and control for the effective development of the community first diagnosis system. [4] The government should focus on expanding the coverage of medical insurance to achieve full coverage of medical insurance as soon as possible; the government should also increase investment in community hospitals, train general practitioners, and guide the flow of talents; the drug proportion is an important indicator to measure patients' medical burdens[5], the government should moderately reduce the drug proportion, improve the value of medical personnel's technical services, and gradually transform the "supporting hospitals by the profits of drugs" into "supporting hospitals by the techniques of doctors", alleviating the problem of residents' "high cost in medical treatment".

\section{B. Residents' Awareness of First Diagnosis in the Community Is Not Strong}

The survey results show that residents' understanding of community health service institutions is not enough, and residents who know well about these institutions account only for $25 \%$. Moreover, after getting ill, 125 people (65.1\%) first chose community health service institutions, 61 (31.8\%) preferred non-community health service institutions, and 6 $(3.1 \%)$ said they would not seek for treatment. Residents' awareness of community first diagnosis is not strong, which has largely hindered the development of community first diagnosis.

In order to truly realize the "treating minor illnesses in community health service institutions, treating serious illnesses in the hospitals", it is necessary to increase the residents' health awareness and their viscosity to the community. The state should vigorously promote the community first diagnosis system, introduce relevant policies on first diagnosis in communities, strengthen policy guidance, and commit to the construction of informatization of medical services, thereby raising residents' awareness of community first diagnosis.

\section{Low Medical Treatment Level in Grass-roots Units and Improper Allocation of Resources}

It is not difficult to see from the survey that residents $(89.1 \%)$ think that it is reasonable to prefer community health service institutions for treatment, and most residents $(81.3 \%)$ think that the level and conditions of medical treatment in community health service institutions have improved compared to the past. The results of multivariate logistic regression analysis also showed that the rationality of preferring community health service institutions for treatment and whether the level and conditions of medical treatment in the community health service institutions have been improved had a significant positive impact on the residents' degree of satisfaction with the community health service institutions. However, it was learned through interviews that even if the medical level and conditions of community health service institutions have improved compared with the past, currently the community health service institutions in Weicheng District of Weifang City still have problems such as low medical treatment level and improper allocation of resources. Especially in drug supply and talent transfer[6] , there is a big gap between community health service institutions and large hospitals. However, with the comprehensive promotion of the family doctor system, the community first diagnosis is constantly achieving effective coverage.

Therefore, establishing a sound family doctor training mechanism, guiding talents to the grassroots units, strengthening the construction of service capacity of community health institutions, and vigorously developing the family doctor system is a powerful driving force for the development of the first diagnosis in the communities. On the issue of medical resources, the government should integrate medical resources and allocate them rationally; strengthen the construction of the medical union, unify the standards, and hospitals in the medical union should recognize the medical results from each other, realizing the sharing and effective allocation of medical resources. [7]

\section{CONCLUSION}

In summary, community health service institutions have the advantages of convenient transportation, low medical expenses, and good service attitude, and have certain advantages in residents' choice of medical institutions. In order to increase residents' degree of satisfaction with community health service institutions, the government should strengthen guidance and support in policies, guide and encourage professional talents to serve the grassroots, improving community health service capabilities, and achieving effective operation of the community first diagnosis mechanism.

\section{REFERENCES}

[1] Li Zaiqiang, Lin Feng. Introduction to the community first diagnosis system of foreign countries[J]. Chinese Health Economics, 2006, 25(2): pp.76-77.

[2] Lu Zuxun, Liu Junan, Peng Ji et al. Analysis of community health service utilization and its influencing factors in Shenzhen City [J]. Chinese Journal of Hospital Administration, 2006, 21 (7): p464. 
[3] Lu Zuxun, Li Wenzhen, Yin Xiaoxu. Discussion on the Necessity of Studying the Feasibility of Community First Diagnosis System[J].Chinese General Practice,2017,20(1):p21.

[4] Huang Pei. The dilemma and countermeasures of the implementation of the first diagnosis in the community from a macro perspective[J].Chinese Journal of Primary Medicine and Pharmacy,2015,22(1):p152.

[5] Yan Junfeng, Xia Xunliang, Zhang Jinan. Problems and discussion in the control of drug proportion in drug management of hospitals[J]. Chinese Journal of Pharmacoepidemiology, 2015, 24(5): p296.

[6] Li Shanshan, Shi Yan, Shi Ping. Analysis of Research Trend Mapping of Graded Diagnosis and Treatment System Based on CiteSpaceV[J]. Chinese Rural Health Service Administration, 2017(10): pp.1167-1170.

[7] Huang Pei, Yi Lihua. Practice and thinking of regional medical union based on graded diagnosis and treatment[J]. Chinese Health Quality Management, 2015, 22(4): p103. 